\title{
Re-solution of Precipitated Silver in Copper-Silver Alloys
}

\author{
by Harold Margolin and Walter R. Hibbard, Jr.
}

$\mathrm{D}$ URING preliminary tests on the aging of a $\mathrm{Cu}$ plus 5 pct Ag alloy, ${ }^{1}$ a specimen which had been overaged $24 \mathrm{hr}$ at $550^{\circ} \mathrm{C}$ was annealed in a nitrogenhydrogen atmosphere first for $2 \mathrm{hr}$ and then for an additional $28 \mathrm{hr}$ at $600^{\circ} \mathrm{C}$. After each anneal the specimen was cooled to room temperature in about $1 / 2 \mathrm{hr}$ and X-ray photograms were made. The first film, Fig. 1a, revealed two sets of copper-base lines, one intense and corresponding to the parameter at $550^{\circ} \mathrm{C}$, the other fainter and shifted away from the beam, corresponding to the larger parameter at $600^{\circ} \mathrm{C}$ (see arrows). The $30-\mathrm{hr}$ film, Fig. $1 \mathrm{~b}$, revealed the same two sets of copper-base lines with a reversal of intensity. In neither case do the copper lines form a broad band which would be indicative of a range of compositions. This phenomenon is thus a "discontinuous" type of solution. A similar phenomenon was observed in a Ag-rich $\mathrm{Cu}-\mathrm{Ag}$ alloy. ${ }^{2}$ Finlay and Hibbard ${ }^{3}$ have suggested that directional rather than random solution of precipitate occurs in some alloys.

Conceivably, for $\mathrm{Cu}-\mathrm{Ag}$ alloys, the matrix-transition-precipitate precipitation sequence is reversible for the re-solution of the precipitate caused by rapidly raising the annealing temperature of an overaged specimen. A copper-base transition structure supersaturated with solute might be formed around the precipitate as it dissolves, thus obviating the necessity for a gradually changing solute composition of the matrix. The solute atoms then might be transferred rapidly and locally from the transition to the matrix phase in the proper amount and at the proper location to obtain directly the new ex-

HAROLD MARGOLIN is Research Associate, Research Div., New York University, New York, and WALTER R. HIBBARD, JR., Member AIME, is Associate Professor of Metallurgy, Yale University, New Haven, Conn.

TN 70E. Manuscript, Dec. 8, 1950

This note is part of a dissertation by Harold Margolin submitted in partial fulfillment of requirements for degree of Doctor of Engineering to Faculty of the School of Engineering, Yale University.

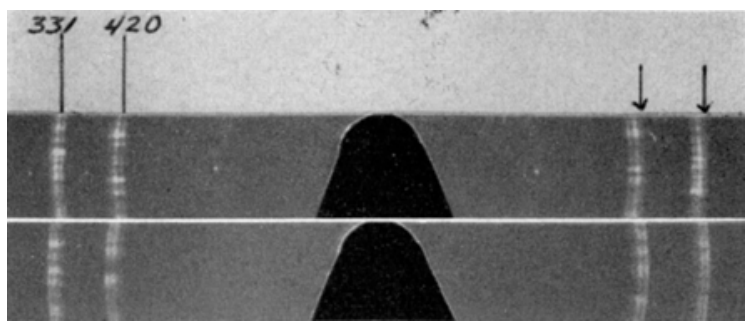

Fig. la (top)- $\mathrm{Cu}-\mathrm{Ag}$ alloy aged $24 \mathrm{hr}$ at $550^{\circ} \mathrm{C}$, annealed $2 \mathrm{hr}$ at $600^{\circ} \mathrm{C}$.

Fig. Ib (bottom)-Same as Fig. 1a, but annealed $30 \mathrm{hr}$ at $600^{\circ} \mathrm{C}$.

panded solid solution. The theory implies a minimum of diffusion of solute in the matrix (i.e., no significant range of matrix composition) and possibly suggests that the composition of the transition structure will vary with the conditions of re-solution. A transition copper phase found in aged $\mathrm{Cu}-\mathrm{Ag}$ alloys ${ }^{1}$ might fulfill this function.

Evidence regarding this suggestion could be obtained in $\mathrm{Cu}-\mathrm{Ag}$ alloys by overaging a specimen until no trace of the expanded copper lattice is present and then subjecting the specimen to a retrogression treatment. Re-appearance of the transition copper phase would confirm the theory. Additional details could be secured by varying both aging and retrogression temperatures.

\section{References}

${ }^{1}$ H. Margolin and W. R. Hibbard, Jr.: Effect of Ternary Additions on the Age Hardening of a CopperSilver Alloy. Trans. AIME (1951) 191, p. 174; JouRnAL of Metals (Feb. 1951) TP 3002E.

${ }^{2}$ N. Ageew, M. Hansen, and G. Sachs: Decomposition and Changes in Properties of Super-saturated SilverCopper Alloys. Ztsch. Physik (1930) 66, p. 350.

${ }^{3}$ W. L. Finlay and W. R. Hibbard, Jr.: Some Effects of Applied Stresses on Precipitation Phenomena. Trans. AIME (1949) 180, p. 255; Metals Technology (Sept. 1948) TP 2470E.

\section{Technical Note}

\section{Fractographic Pattern for $475^{\circ} \mathrm{C}$ Embrittlement in Stainless Steel}

\author{
by Carl A. Zapffe
}

$\mathrm{F}$ OR a number of years a puzzling phenomenon of brittleness in Class II ferritic stainless steels, developing in the temperature range near $475^{\circ} \mathrm{C}$, has received increasing attention, but its nature remains essentially unknown. During an investigation of the fractographic structures in stainless steels, conducted in the author's laboratory the past several years, principally under sponsorship of the Office of
Naval Research, some observations of a new kind were found for " $475^{\circ} \mathrm{C}$ embrittlement."

While the details of the study cannot be given here, ${ }^{1}$ three fractographs will suffice to carry the

CARL A. ZAPFFE, Member AIME, is Consulting Metallurgist, Baltimore.

TN 54E. Manuscript, Nov. 24, 1950. 